\title{
The impact and measurement of social dysfunction in late- life depression: an evaluation of current methods with a focus on wearable technology
}

\author{
Sophie Hodgetts ${ }^{1}$, Peter Gallagher ${ }^{1,2}$, Daniel Stow ${ }^{1}$, I. Nicol Ferrier ${ }^{1}$ and John T. O’Brien ${ }^{3}$ \\ ${ }^{1}$ Institute of Neuroscience, Newcastle University, Newcastle upon Tyne, UK \\ ${ }^{2}$ Newcastle University, Institute for Ageing, Newcastle upon Tyne, UK \\ ${ }^{3}$ Department of Psychiatry, University of Cambridge, Cambridge, UK \\ Correspondence to: Dr Peter Gallagher, E-mail: peter.gallagher@newcastle.ac.uk
}

\begin{abstract}
Objective: Depression is known to negatively impact social functioning, with patients commonly reporting difficulties maintaining social relationships. Moreover, a large body of evidence suggests poor social functioning is not only present in depression but that social functioning is an important factor in illness course and outcome. In addition, good social relationships can play a protective role against the onset of depressive symptoms, particularly in late-life depression. However, the majority of research in this area has employed self-report measures of social function. This approach is problematic, as due to their reliance on memory, such measures are prone to error from the neurocognitive impairments of depression, as well as mood-congruent biases.
\end{abstract}

Method: Narrative review based on searches of the Web of Science and PubMed database(s) from the start of the databases, until the end of 2015.

Results: The present review provides an overview of the literature on social functioning in (late-life) depression and discusses the potential for new technologies to improve the measurement of social function in depressed older adults. In particular, the use of wearable technology to collect direct, objective measures of social activity, such as physical activity and speech, is considered.

Conclusion: In order to develop a greater understanding of social functioning in late-life depression, future research should include the development and validation of more direct, objective measures in conjunction with subjective self-report measures. Copyright (C) 2016 John Wiley \& Sons, Ltd.

Key words: late-life depression; social function; self-report; wearable technology

History: Received 03 March 2016; Accepted 26 October 2016; Published online in Wiley Online Library (wileyonlinelibrary.com)

DOI: 10.1002 /gps.4632

\section{Introduction}

It is now well-established that the impact of depression goes beyond the core symptoms of depressed mood and anhedonia. For example, patients with depression typically demonstrate a significant amount of social dysfunction. Specifically, patients often experience difficulties, maintaining social relationships, such as with family and friends. Such dysfunction can place additional stress on these relationships, creating a negative cycle which contributes to the recurrence of depressive episodes (Hirschfeld et al., 2000).
The impact of decreased social functioning is potentially greater in older adults with depression, with several reports suggesting that this population in particular is at risk of increased isolation and loneliness (Isaac et al., 2009). To date, the majority of studies investigating social functioning in depression have relied on self-report, questionnaire-based measures of social function. However, these measures are subject to several limitations, which in turn, impact our current understanding of social functioning in late-life depression. Therefore, the present review was conducted to highlight specific ways in which current 
measures are lacking and introduce possible new methods for measuring social function that are not subject to such limitations, with a particular focus on wearable technology. This paper will present a review of the literature on the social functioning in depressed older adults, in which the effect of depression on social function, and the potentially protective effects of good social relationships has been investigated. We will then present an evaluation of the methods commonly used to assess social functioning, before discussing the potential for new technologies, and particularly wearable devices, to improve our ability to measure social functioning in late-life depression.

\section{Depression in later life}

Depression is a common psychiatric illness with extensive personal and economic implications for patients, their families and society in general (Hirschfeld et al., 2000; Kessler et al., 2003). Moreover, depression is purported to be the most common cause of emotional suffering in later life (Blazer et al., 1987; Blazer et al., 1991; Schwarzbach et al., 2014). Consequently, late-life depression (LLD) has become a topic of significant research interest (Adams \& Moon, 2009). Although other mental health disorders are known to interact with social functioning (Wolitzky-Taylor et al., 2010), there is a need to study depression in particular, due to its high prevalence (13.3\%; Beekman, Copeland \& Prince, 1999) and significant effect on emotional suffering and activities of daily living (Colloby, et al., 2011). Therefore, this review will focus on depression in later life.

Late-life depression is associated with increased risk of suicide, increased morbidity risk, decreased social functioning, impaired cognitive functioning and greater self-neglect, than MDD in earlier life (Fiske et al., 2009; Blazer, 2003), compared with depression earlier in the lifespan. Late-life depression may also worsen the outcome of several medical conditions (Alexapoulos, 2005), is a strong determinant of disability in older people (Barry et al., 2011) and is a recognised risk factor for the development of dementia (Blazer et al., 2003). Studies have shown that the magnitude of neurological impairments associated with depression is typically greater in older, rather than younger patients (Fiske et al., 2009; Alexapoulos, 2005) and that this is not due to the ageing process alone (Thomas et al., 2009). Memory impairment is a typical feature of LLD (Thomas et al., 2009; O'Brien et al., 2004; Sheline et al., 2006), and executive functioning is affected to a greater extent in late onset depression compared with early onset (Alexapoulos, 2005; Butters et al., 2004; Hermann et al., 2007).

The importance of research into LLD becomes clear when the effect of population ageing is considered. Population ageing is a global phenomenon defined by the United Nations as the rising proportion of older people within the total population (United Nations, Department of Economic and Social Affairs, Population Division, 2013). In the UK, recent estimates suggest that $23 \%$ of the population will be aged $65+$ years and over and 5\% will be aged $85+$ years by 2035 (Office for National Statistics, 2012). Therefore, it is likely that LLD, and the complications associated with LLD, will become a significant challenge to current healthcare systems. Critically, in order to improve the assessment of function in patients and, in turn, improve outcomes, there is a need to develop a greater understanding of the psychosocial impact of depression in older adults.

\section{Search strategy and selection criteria}

The initial literature search was conducted in a systematic manner, searching the Web of Science and PubMed database(s) from the start of the databases, until to the end of 2015. Various search terms were used to identify papers related to LLD and measures of social functioning. To identify papers related to LLD, we used the following search terms: old ${ }^{\star}$ OR elde ${ }^{\star}$ OR age ${ }^{\star}$ OR geriatric OR (late life) OR 60+ OR 65+ OR 85+ OR senior; Depress ${ }^{\star}$ OR Unipolar OR LLD OR (mood disorder) OR affect*. To identify papers related to (self-report) measures of social dysfunction, the following terms were used: measure OR assess $^{\star}$ in conjunction with psychosocial OR social ${ }^{\star}$ OR satisfaction $\mathrm{OR}$ wellbeing $\mathrm{OR}$ well-being $\mathrm{OR}$ support OR relations ${ }^{\star}$. To identify papers related to direct, objective measures of social activity (e.g. measures of speech and/or physical activity), the following terms were used: Speech OR vocalisation OR prosody OR pitch OR dynamics, phys ${ }^{\star}$ OR activity OR exercise $^{\star}$ OR Accelerometer ${ }^{\star}$ OR Actigraph ${ }^{\star}$ OR movement. While we focussed on papers published within the last 5 years, we did not exclude highly cited and highly regarded older publications. In addition, we scanned the reference lists of the identified papers and selected further papers according to their perceived relevance. This led to the inclusion of unpublished thesis work in the present review. Additional reviews are cited in order to direct the reader to further details on issues beyond the scope of the present review. 


\section{Social functioning in depression}

Recently, much research into mental health in later life has concerned social functioning, and the effect of LLD on relationships between the patient and their family/ friends (Schwarzbach et al., 2013). Such research has typically investigated either the effect of depression on social functioning, or the potentially protective role of good social relationships against depression (Table 1).

Typically, social functioning is assessed using selfreport questionnaires or ecological momentary assessments. Self-report questionnaires include the Duke Social Support Index (Bosworth et al., 2002; Riddle et al., 2015), the Family Support Satisfaction Scale

Table 1 Summary of studies using self-report/questionnaire methods to evaluate social function and social support in late life depression

\begin{tabular}{|c|c|c|c|c|}
\hline $\begin{array}{l}\text { Measure/ } \\
\text { Questionnaire }\end{array}$ & $\begin{array}{l}\text { Studies using } \\
\text { the measure }\end{array}$ & Measure details & Strengths & Limitations \\
\hline $\begin{array}{l}\text { Duke Social } \\
\text { Support Index } \\
\text { (Koening et al., } \\
\text { 1993) }\end{array}$ & $\begin{array}{l}\text { George et al., } \\
\text { 1989; } \\
\text { Bosworth et } \\
\text { al., 2001; } \\
\text { Riddle et al., } \\
2015\end{array}$ & $\begin{array}{l}\text { A self-report scale designed to } \\
\text { generate information on four } \\
\text { dimensions of social support: size } \\
\text { of social network, amount of } \\
\text { social interaction, amount of } \\
\text { instrumental support, and } \\
\text { subjective social support. }\end{array}$ & $\begin{array}{l}\text { Good reliability and validity } \\
\text { Assesses a range of concepts } \\
\text { related to social support }\end{array}$ & $\begin{array}{l}\text { Subject to self-report bias (i.e. } \\
\text { mood, poor memory) }\end{array}$ \\
\hline $\begin{array}{l}\text { Family } \\
\text { Support } \\
\text { Satisfaction } \\
\text { Scale }\end{array}$ & $\begin{array}{l}\text { Tanner et al., } \\
2014\end{array}$ & $\begin{array}{l}\text { Thirteen dichotomous items, } \\
\text { constructed to assess participant } \\
\text { satisfaction with affective social } \\
\text { support provided by family } \\
\text { members, and subjective } \\
\text { perception of social integration } \\
\text { and assistance provided by family } \\
\text { members. }\end{array}$ & $\begin{array}{l}\text { Assesses patient satisfaction } \\
\text { with several different types of } \\
\text { support that might be } \\
\text { provided by family members. }\end{array}$ & $\begin{array}{l}\text { Subject to self-report bias (i.e. } \\
\text { mood, poor memory). } \\
\text { Dichotomous items only. } \\
\text { Limited to family-based social } \\
\text { support/integration }\end{array}$ \\
\hline $\begin{array}{l}\text { Social Support } \\
\text { Scale }\end{array}$ & $\begin{array}{l}\text { Tanner et al., } \\
2014\end{array}$ & $\begin{array}{l}\text { Three Likert scale items designed } \\
\text { to assess participants' } \\
\text { perceptions of loneliness and } \\
\text { support availability from family/ } \\
\text { friends. }\end{array}$ & $\begin{array}{l}\text { Short, easy to administer and } \\
\text { not over-burdensome on } \\
\text { participants. }\end{array}$ & $\begin{array}{l}\text { Three items only. } \\
\text { Subject to self-report bias (i.e. } \\
\text { mood, poor memory). }\end{array}$ \\
\hline $\begin{array}{l}\text { Social contact } \\
\text { intensity } \\
\text { (single-item } \\
\text { measure) }\end{array}$ & $\begin{array}{l}\text { Robitaille et } \\
\text { al., } 2014\end{array}$ & $\begin{array}{l}\text { Single, study-specific item asking } \\
\text { participants how many people } \\
\text { they see. }\end{array}$ & $\begin{array}{l}\text { Short, easy to administer, can } \\
\text { be included as part of } \\
\text { questionnaire battery, and not } \\
\text { over-burdensome on } \\
\text { participants. }\end{array}$ & $\begin{array}{l}\text { Only assesses the number of } \\
\text { people seen by the participant, } \\
\text { no measure of quality of } \\
\text { interaction. } \\
\text { Subject to self-report bias (i.e. } \\
\text { mood, poor memory). }\end{array}$ \\
\hline $\begin{array}{l}\text { Social Factors } \\
\text { Questionnaire } \\
\text { (dichotomised } \\
\text { questions) }\end{array}$ & $\begin{array}{l}\text { Sjoberg et al., } \\
2013\end{array}$ & $\begin{array}{l}\text { Series of dichotomised questions } \\
\text { designed to assess the presence } \\
\text { or absence of daily contact with } \\
\text { others (either by telephone or } \\
\text { email), visits from family/friends, } \\
\text { feelings of loneliness, and } \\
\text { participation in hobbies. }\end{array}$ & $\begin{array}{l}\text { Assess the presence or } \\
\text { absence of a range of factors } \\
\text { related to social support, as } \\
\text { well as the subjective feeling } \\
\text { of loneliness. }\end{array}$ & $\begin{array}{l}\text { Dichotomised items assessing } \\
\text { only the presence or absence of } \\
\text { support (i.e. no measure of } \\
\text { quality of support) } \\
\text { Subject to self-report bias (i.e. } \\
\text { mood, poor memory). }\end{array}$ \\
\hline $\begin{array}{l}\text { Assessment of } \\
\text { social support }\end{array}$ & $\begin{array}{l}\text { Lee et al., } \\
\text { 2012; Liang } \\
\text { et al., 1999; } \\
\text { Lue et al., } \\
2010\end{array}$ & $\begin{array}{l}\text { Eight item assessment designed } \\
\text { to assess the participant's } \\
\text { perceived level of social support, } \\
\text { and their satisfaction with the } \\
\text { support they received. }\end{array}$ & $\begin{array}{l}\text { Short, easy to administer. } \\
\text { Produces a score to provide a } \\
\text { measure of perceived quality } \\
\text { of social support }\end{array}$ & $\begin{array}{l}\text { Subject to self-report bias (i.e. } \\
\text { mood, poor memory). }\end{array}$ \\
\hline $\begin{array}{l}\text { Assessment of } \\
\text { social activity }\end{array}$ & $\begin{array}{l}\text { Lee et al., } \\
2012\end{array}$ & $\begin{array}{l}\text { Seven item assessment designed } \\
\text { to measure the participant's level } \\
\text { of involvement in a range of social } \\
\text { activities (e.g. community } \\
\text { organisations, religious groups, } \\
\text { family events). }\end{array}$ & $\begin{array}{l}\text { Assess the presence or } \\
\text { absence of a range of social } \\
\text { activities }\end{array}$ & $\begin{array}{l}\text { Dichotomised items assessing } \\
\text { only the presence or absence of } \\
\text { support (i.e. no measure of } \\
\text { quality/satisfaction with social } \\
\text { activities). } \\
\text { Subject to self-report bias (i.e. } \\
\text { mood, poor memory). }\end{array}$ \\
\hline $\begin{array}{l}\text { Ecological } \\
\text { momentary } \\
\text { assessments }\end{array}$ & $\begin{array}{l}\text { Barnett \& } \\
\text { Gotlib, 1988; } \\
\text { Gotlib \& Lee, } \\
\text { 1987; Stone } \\
\text { et al., } 1998\end{array}$ & $\begin{array}{l}\text { Participant is asked to make } \\
\text { repeated assessments of their } \\
\text { social activity throughout the day. }\end{array}$ & $\begin{array}{l}\text { Assesses recent social } \\
\text { experiences and so places } \\
\text { fewer demands on memory. }\end{array}$ & $\begin{array}{l}\text { Frequent reports of low } \\
\text { adherence when used in } \\
\text { psychiatric samples. } \\
\text { Subject to self-report biases } \\
\text { such as mood and poor memory } \\
\text { (albeit to a lesser degree than } \\
\text { other self-report measures). }\end{array}$ \\
\hline
\end{tabular}


(Tanner et al., 2014), the Social Support Scale (De Guzman et al., 2015). Additional studies have used single-item self-report scales (e.g. Robitaille et al., 2014), dichotomised questions (e.g. Sjoberg et al., 2013) or self-ratings of social involvement/participations (e.g. Lee et al., 2012). Other studies have relied on ecological momentary assessments (EMA) of social functioning. This method requires the patient to make repeated assessments of their social activity, in real-time and in their natural environment (Stone et al., 1998). Although this method still relies heavily on self-report, EMAs typically assess recent experiences and thus are less reliant upon retrospective recall. Studies using such self-report methods have shown that depressed patients report fewer intimate relationships (Gotlib \& Lee, 1987), reduced participation in social activities/low social integration (Barnett \& Gotlib, 1988; Gotlib \& Lee, 1987), are less active within their family roles, but are prone more to arguments with family members and/or marital distress (Barnett \& Gotlib, 1988; Gotlib \& Lee, 1987), and have smaller social networks (see Gotlib, 1992 for a review).

\section{Social relationships as a protective factor against} depression

It is important to accurately measure social relationships in LLD patients, because studies show that poor social functioning is not only present in LLD but that social functioning is an important factor in illness onset, course and outcome (Schwarzbach et al., 2014). These studies typically suggest that (good) social relationships can play a protective role against the onset of depressive symptoms and can be beneficial during treatment. For example, Issac et al. (2009) reported that higher social activity was negatively associated with case-level depressive symptomatology. In a prospective analysis, this study showed that high social activity was associated with symptom improvement. Similarly, Tanner et al. (2014) demonstrated that decreased satisfaction with family support and increased loneliness were significant predictors of depression. In a 12-month longitudinal study, Bosworth et al. (2002) reported that patients who did not achieve remission reported decreased subjective social support at baseline compared with those in remission. Prince et al. (1997) reported that a perceived lack of social support directly related to depression, while Lee et al. (2012) showed that social support was a significant predictor of improvement in depression. Similarly, Chi and Chou (2001) demonstrated that social support from family related to depressive symptomatology.
Mechakra-Tahiri et al. (2009) showed that social support and lack of conflict in intimate relations (e.g. with spouse and children) was associated with less depressive symptoms, while Sugisawa et al. (2002) showed that increased contact with friends, neighbours and relatives, as well as having a spouse, was associated with fewer depressive symptoms. Taken together, these findings suggest that the presence of (good) social relationships is beneficial to the reduction of depressive symptoms in older adults.

It has been argued that negative life events, as potential triggers for MDD, are more common to the onset of LLD than MDD in younger adults (Tanner et al., 2014). Such negative events include death of spouse/friends, chronic illnesses (leading to changes in physical and/or cognitive ability) and loss of social roles (Fiske et al., 2009; Prince et al., 1997). Fiest et al. (2011) report a higher prevalence of MDD in older adults with one chronic condition (such as arthritis, asthma or diabetes) compared with those without (3.7\% and 1\%, respectively). Marks (2013) reported that more than $20 \%$ of a sample of older adults with knee osteoarthritis met the diagnostic criteria for MDD. Likewise, disability is common in later life and is a widely acknowledged risk factor for LLD (Bruce, 2001). However, many individuals with a disability report a high quality of life, and Jang et al. (2002) argue that good social functioning is related to this. In this study, greater satisfaction with social support was associated with a reduced effect of disability on depression scores in older adults, as compared with patients less satisfied with their social support. More recently, it has been suggested that the relationship between negative life events and LLD is circular, such that negative events may predict LLD symptoms, and in turn, LLD may predict further negative life events (Fiske et al., 2009; Alexandrino-Silva, 2011). As such, good social functioning (and good social support) may be important to break this effect, acting as a buffer against the effect of negative life events and/or MDD symptoms.

Thus, in addition to the 'mere presence' of social relationships, the quality of the relationships as well as the patient's subjective feelings regarding the relationships are also important factors in LLD. Specifically, poor quality social relationships have been highlighted as a risk factor for depression in older adults. In a 10-year follow-up study of a large sample of adults $(n=4642)$, Teo et al. (2013) demonstrated an increased risk of depression in those reporting greater social strain and poor relationship quality at baseline. Specifically, respondents with the lowest quality of social relationships (e.g. reporting that 
spouse/family/friends made too many demands, were highly critical and not reliable) had more than double the risk of depression than those with the highest social relationship quality (although it should be noted that this study did not exclusively investigate older adults). Similarly, a number of studies suggest that the subjective feeling of loneliness is strongly related to higher depression scores (Alpass \& Neville, 2003; Cacioppo et al., 2006). Moreover, following a large systematic review, Forsman et al. (2011) conclude that psychosocial interventions aimed at strengthening social networks and reducing loneliness were particularly effective at reducing depressive symptoms in older patients.

Although much evidence to date suggests that social relationships and social functioning are important in LLD, an open question remains regarding the direction of the relationship. Specifically, questions remain regarding causality: is poor social functioning caused by LLD, or does poor social functioning cause LLD? Currently, the consensus of the literature is that the relationship between LLD and social functioning in likely bidirectional. For example, the cardinal symptoms of MDD (such as anhedonia, irritability and becoming withdrawn) likely directly contribute to poor social functioning in patients (Steger \& Kasdan, 2009). Similarly, MDD has frequently been associated with impaired social cognition, for example, impaired emotion recognition (Szanto et al., 2012) and Theory of Mind deficits (Lee et al., 2005; Wolkenstein et al., 2011; for a recent review, see Billeke et al., 2013). In addition, there is evidence to suggest that a diagnosis of MDD (and the symptoms of MDD) may, in turn, lead to reduced trust from the patients' social contacts on account of the stereotypes associated with a mental health diagnosis (Aromaa et al., 2012). In turn, there is evidence to suggest that poor social situations (e.g. lack of social support, such as during a negative life event) could also be a triggering factor for LLD or play a role in illness maintenance (i.e. lack of support during treatment/illness; Alexandrino-Silva, 2011).

\section{Interaction with other issues in late-life depression}

Still further research has suggested that poor social functioning in LLD may mediate other issues related to the illness. For example, a recent study demonstrated that LLD patients with a history of suicide attempts reported restricted social networks (less likely to talk to their children, fewer close friends), hostility in relationships and a lack of social support as compared with non-suicidal LLD patients (Szanto et al.,
2012; see also Duberstein et al., 2004). Szanto et al. (2012) also demonstrated poor social emotion recognition and poor global cognition in suicidal LLD patients, relative to both healthy controls and nonsuicidal LLD patients. Consequently, the authors argue that cognitive decline and social deficits likely interact and lead to an increased risk of suicidality in LLD (Wiktorsson et al., 2010). Still, further research suggests that social support can mediate the effects of LLD on other aspects of the patient's life. For example, Litwin (2012) reported that older adults with restricted social networks are most at risk of decreased physical activity and in turn, more depressive symptoms. Moreover, Travis et al. (2004) found that while a depression diagnosis per se was not directly associated with any measures of disability, lack of social support and less social interaction were associated with instrumental (activities not necessary for fundamental functioning, e.g. housework and use of telephone) and basic (activities necessary for fundamental functioning, e.g. bathing, dressing and self-feeding) disability, respectively (see also Stuck et al., 1999). Jeste et al. (2006) demonstrated that LLD patients with comorbid anxiety reported poor subjective social support, as well as increased suicidality. These authors suggest that interventions designed to improve subjective social support might prove beneficial for anxious LLD patients.

\section{Limitations of current measures of social functioning in late-life depression}

The methods employed by the majority of the aforementioned studies rely on the patient accurately, recalling autobiographical events. However, this is an ability that can be compromised by the cognitive impairments associated with LLD, as well as by ageing in general (Thomas et al., 2009; O'Brien et al., 2004; Butters et al., 2004; Sheline et al., 2006). For example, Thomas et al. (2009) demonstrated extensive neurocognitive impairments in LLD, including in verbal learning and memory (measured using the Rey Auditory Verbal Learning test), with LLD patients performing significantly worse than younger MDD patients. Additional studies have more directly demonstrated that such measures are susceptible to error (Stone et al., 1998; Rabbi et al., 2011; Haywood et al., 2005). Furthermore, there is a large body of research demonstrating that memory processes in depression are characterised by mood-congruent biases, such that patients recall and interpret events as more negative as compared with healthy controls (Gotlib, 1983; Romero et al., 2014; Watkins et al., 1996). 
Moreover, the requirement of EMAs to be conducted repeatedly has proved problematic in psychiatric populations, with some studies reporting low adherence in mood-disordered patients (see Wenze \& Miller, 2010 for a review). Taken together, these issues may result in missing data and/or self-reports of social activity that are influenced by negative biases. Therefore, it is perhaps unsurprising that following a review of research on social cognition in MDD, Billeke et al. (2013) conclude that studies using 'more ecologically valid biomarkers' are required.

\section{The use of wearable technology in depression}

The ability to obtain direct, objective measures of social functioning in older adults with depression would represent a significant improvement in the assessment tools available when compared with self-reports, such as questionnaires or EMAs, alone. Wearable technology is a potential method to collect such data. This method typically requires the patient to wear a small device, often as a wristwatch or a waist-mounted device, containing small sensors, such as an accelerometer. Moreover, the development of wearable technologies will provide objective data that should allow more detailed research to examine important cultural effects and condition differences in self-report and questionnaire-based measures and allow investigation of their sensitivity and specificity. Previous work using such technology in MDD patients has yielded promising results. For example, early studies of physical activity in depression were also reliant on self-report questionnaires. However, more recent studies have used the Actigraph system, a wearable accelerometer system which is able to measure physical activity in everyday situations in great detail. The usefulness of such a device to assess physical activity in patients with mood disorders has previously been acknowledged (Teicher, 1995) and has been shown to yield more precise measurements than self-report measures (Sabia et al., 2014; Prince et al., 2008; for a review, see Burton et al., 2013). For example, following a systematic review, Prince et al. (2008) concluded that as self-report measures were often either higher or lower than directly measured activity levels, reliance on such measures is problematic. However, in order to objectively address aspects of social functioning in LLD, there is a need to quantify the amount and quality of social activity in a patient's everyday life.

One possible method of objectively measuring social activity is by directly measuring the amount of speech the patient engages in. A number of recent technological advances mean it is now possible to record how long and/or how often a patient engages in conversation, as well as how much speech the patient contributes to a conversation relative to others, in such a way that the patient's privacy is maintained. These measures can then be combined with others, such as self-report measures. For example, Maxhuni et al. (2011) combined speech data and EMA measures of mood to investigate the relationship between social interaction and mood in the workplace. In this study, social interaction was defined as the sum of minutes the participant spent talking, as measured by smart phone microphones. The results showed a positive correlation between the amount of social interaction and positive mood states, as assessed via EMA. However, Rabbi et al. (2011) present a case study (as part of a larger study of older adults), demonstrating a significant discrepancy between directly measured speech and self-reported mental health and social integration. Specifically, while the questionnaire data suggested no mental health concerns, the speech data suggested a very low level of speech in a conversational context, which raised concerns regarding social isolation. Moreover, the speech data corresponded with direct observations of the patient, made by a medical trainee. Consequently, the authors suggest that the questionnaire data may have been influenced by factors such as misinterpretation of the questions, and direct measurements could be used to provide more accurate measures that do not depend on accurate recall or interpretation on behalf of the patient.

In light of the evidence provided by Rabbi et al. (2011), as well as the aforementioned limitations of self-report measures, particularly when used in the LLD population, a more attractive option is to use multi-modal assessments (Godfrey \& Knight, 1984). For example, it is possible to use wearable technology to directly measure both physical activity and speech, in order to gain a more complete picture of how depression affects the patient's day-to-day life. Indeed, with the exception of the aforementioned case study, Rabbi et al. (2011) report that direct measures of speech and physical activity 'correlate highly' (p. 393) with several well-established questionnaires. Similarly, Choudry and Pentland (2002) demonstrate that speech and movement data, gathered using a 'sociometer', can be used to analyse the wearer's face-to-face interactions (including the frequency and duration of conversations, and wearer's contribution to the conversations). Moreover, using various modelling techniques, this data can be used to investigate the structure and dynamics of the wearer's social network (Choudry \& Pentland, 2002). 
While the use of such multi-modal measures appears promising in the assessment of social functioning, to date, their use in psychiatric populations has been limited to mood monitoring. For example, Chang (2012) demonstrated that speech analysis via mobile phones could be used to assess and classify the users' current mood state. Such technology has clear potential applications for mental health monitoring. Indeed, Prociów (2011) presents a case study in which smartphone technology was used to monitor movement and social activity in a euthymic bipolar patient. In conjunction with an additional study in healthy controls (Prociów \& Crowe, 2010), the authors conclude that speech data may prove useful in the early detection of upcoming manic/depressive episodes. A recent study by Karam et al. (2014) expands these findings by demonstrating that speech data (collected through day-to-day mobile phone conversations) can be used to accurately classify hypomanic, depressed and euthymic states in bipolar disorder (Muaremi et al., 2014). Similar research has also been conducted in MDD populations. Cummins et al. (2013) showed that specific features of speech (such as spectral variability) could be used to assess the severity of depressive symptoms (Sturim et al., 2011). Moreover, Ooi et al. (2013) demonstrated that speech data could be used to predict MDD onset in at-risk adolescents, 2 years prior to symptom onset, with $73 \%$ accuracy. Taken together, these findings suggest that speech data are potentially a rich source of information relevant to the monitoring of various psychiatric conditions.

The use of objective measures, such as speech data, to assess social functioning in LLD is yet to be investigated. However, the findings discussed earlier suggest that speech monitoring (via wearable technology or mobile phones) is a feasible option for this population. Indeed, a recent study has shown that wearable technology is acceptable to patients with LLD and that it has the potential to provide accurate, objective measures of real-world functioning in this population (O'Brien et al., 2016). In this study, activity levels were assessed in 29 patients with LLD via a bespoke, wristworn activity monitor. The authors report that the device was designed to be as unobtrusive and as comfortable as possible, designed much like a standard wristwatch with an adjustable silicone band and stainless-steel fastening. Home visits by the research team were arranged to replace monitors needing to be recharged with identical, fully charged monitors. In addition to a significant reduction in physical activity in patients with LLD, the authors report a high level of compliance with the monitor in both the depressed patients $(92.2 \%)$ and the elderly control participants
(92.3\%). Taken together, this study suggests that wearable technology is a feasible option for monitoring physical activity (and, potentially, social functioning) in older populations.

Moreover, wearable technology may be more sensitive to changes in social functioning compared with current self-report based measures (e.g. Rabbi et al., 2011). Improving the accuracy with which social functioning is measured is important for several reasons. Firstly, as highlighted at the beginning of this review, social functioning is negatively affected by depression and as such, is a potential target for treatment. Indeed, studies suggest that patients rate improvements in social functioning as a particularly important treatment outcome (Billeke et al., 2013). Therefore speech data have the potential to be an ecologically valid outcome measure. Secondly, good social functioning has been shown to play a protective role against LLD. Accurate measures are important in this respect, as they may be used to highlight need to improve the patient's social situation; self-report measures can fall short in this respect, as demonstrated by Rabbi et al. (2011). Furthermore, using technology in this way means that information on social functioning can be gathered in everyday situations, with minimal inconvenience or interruption to the patient's daily routine. Thus, patient adherence to the assessment procedure is likely to improve.

In conclusion, it is clear from the evidence discussed earlier that social functioning is an important aspect of LLD. While social function is significantly impaired by depressive symptoms, the presence of good social relationships and good social support plays an important protective role against depression in later life. However, much research to date has relied on self-report based assessments of social functioning, and these methods are subject to several limitations. The use of wearable technology, such as accelerometers and mobile phones, offers promising new methods of assessing social functioning directly. Specifically, the use of multi-modal (movement and speech) data has been shown to provide a large amount of ecologically valid data in an unobtrusive way. Such technologies also offer new ways of remotely monitoring older populations. For example, speech and movement data can be electronically transferred to clinicians to create detailed records, and up-to-date, precise information (Bloom et al., 2015). Indeed, the use of technology in this way will likely be of great assistance in the management of an ageing population. For example, in addition to their aforementioned research utility, devices such as the one reported by O'Brien et al. (2016) have the potential for 
use in clinical contexts, such as in the detection of illness onset in 'at risk' individuals, relapse detection/ prevention or to monitor outcomes in patients as they undergo treatment. However, it is critical that other measures, such as subjective questionnaires, clinical assessments and clinical judgments, should not be ruled out entirely as there is evidence to suggest that the subjective components of social functioning are important to LLD patients (e.g. Chi and Chou, 2001). In order to create a full, detailed picture of social functioning in LLD, future research should aim to include direct, objective measures in conjunction with subjective assessments.

\section{Conflict of interest}

The authors are currently involved in the DEMOPOD study (The Development and Evaluation of a Monitoring device to Objectively assess functional and Psychosocial impairment in Older-age adults with major Depression).

Key points

- Social relationships are a protective factor against depression.

- The majority of research in this area has relied on problematic self-report measures.

- Wearable technology is a promising new method for the collection of objective data on social functioning.

\section{Acknowledgements}

The authors thank Roisin McNaney and Dan Hedley for their assistance with early drafts of the manuscript. This study was funded by an award from the UK Medical Research Council (G1001828/1). JTO'B is supported by the NIHR Biomedical Research Centre and Biomedical Research Unit in Dementia awarded to Cambridge University Hospitals NHS Trust and the University of Cambridge and the study was supported by the NIHR Biomedical Research Centre awarded to Newcastle upon Tyne Hospitals NHS Trust and Newcastle University. P. G., I. N. F. and D. S. received Research Capability Funding from the Northumberland, Tyne and Wear NHS Foundation Trust, which also supported this project. Part of this work has been funded by the RCUK Digital Economy Research Hub on Social Inclusion through the Digital Economy (SiDE) [EP/G066019/1].

\section{References}

Adams KB, Moon H. 2009. Subthreshold depression: characteristics and risk factors among vulnerable elders. Aging Ment Health 13: 682-692. DOI:10.1080/ 13607860902774501.

Alexandrino-Silva C, Alves TF, Tofoli LF, Wang Y-P, Andrade LH. 2011. Psychiatry life events and social support in late life depression. Clinics 66: 233-238. DOI: $10.1590 / \mathrm{s} 1807-59322011000200009$.

Alexapoulos GS. 2005. Depression in the elderly. Lancet 365: 1961-1970. DOI:10.1016/s0140-6736(05)66665-2.

Alpass FM, Neville S. 2003. Loneliness, health and depression in older males. Aging Ment Health 7: 212-216. DOI:10.1080/1360786031000101193.

Aromaa E, Tolvanen A, Tuulari J, Wahlbeck K. 2011. Predictors of stigmatizing attitudes towards people with mental disorders in a general population in Finland. Nord J Psychiatry 65: 125-132. DOI:10.3109/08039488.2010.510206.

Barnett PA, Gotlib IH. 1988. Psychosocial functioning and depression distinguishing among antecedents, concomitants, and consequences. Psychol. Bull. 104: 97-126. DOI:10.1037/0033-2909.104.1.97.

Barry LC, Murphy TE, Gill TM. 2011. Depressive symptoms and functional transitions over time in older persons. Am J Geriatr Psychiatry 19: 783-791. DOI:10.1097/JGP.0b013e3181ff6669.

Beekman AT, Copeland JR, Prince MJ. 1999. Review of community prevalence of depression in later life. The British Journal of Psychiatry 174(4): 307-311.

Billeke P, Boardman S, Doraiswamy PM. 2013. Social cognition in major depressive disorder: a new paradigm? Transl Neurosci 4: 437-447. DOI:10.2478/s13380-0130147-9.

Blazer D, Burchett B, Service C, George LK. 1991. The association of age and depression among the elderly - an epidemiologic exploration. J. Gerontol 46: M210-M215.

Blazer D, Hughes DC, George LK. 1987. The epidemiology of depression in an elderly community population. Gerontologist 27: 281-287.

Blazer DG. 2003. Depression in late life: review and commentary. J. Gerontol. 58: 249-265.

Bloom DE, Chatterji S, Kowal P, et al. 2015. Macroeconomic implications of population ageing and selected policy responses. Lancet 385: 649-657. DOI:10.1016/ s0140-6736(14)61464-1.

Bosworth HB, Hays JC, George LK, Steffens DC. 2002. Psychosocial and clinical predictors of unipolar depression outcome in older adults. Int J Geriatr Psychiatry 17: 238-246. DOI:10.1002/gps.590.

Bruce ML. 2001. Depression and disability in late life - Directions for future research. Am J Geriatr Psychiatry 9: 102-112. DOI:10.1176/appi.ajgp.9.2.102.

Burton C, McKinstry B, Tatar AS, et al. 2013. Activity monitoring in patients with depression: a systematic review. J. Affect. Disord. 145: 21-28. DOI:10.1016/j. jad.2012.07.001.

Butters MA, Whyte EM, Nebes RD, et al. 2004. The nature and determinants of neuropsychological functioning in late-life depression. Archives Gen. Psychiatry 61: 587-595. DOI:10.1001/archpsyc.61.6.587.

Cacioppo JT, Hughes ME, Waite LJ, Hawkley LC, Thisted RA. 2006. Loneliness as a specific risk factor for depressive symptoms: cross-sectional and longitudinal analyses. Psychol. Aging 21: 140-151. DOI:10.1037/0882-7974.21.1.140.

Chang K. 2012. Speech Analysis Methodologies towards Unobtrusive Mental Health Monitoring (Unpublished Doctoral Dissertation). University of California at Berkeley: USA.

Chi I, Chou KL. 2001. Social support and depression among elderly Chinese people in Hong Kong. Int J Aging Hum Dev. 52: 231-252.

Choudhury T, Pentland A. 2002. The Sociometer: A Wearable Device for Understanding Human Networks. In In the Workshop Proceedings of Computer Supported Cooperative Work (Workshop: Ad hoc Communications and Collaboration in Ubiquitous Computing Environments). LA: New Orleans.

Colloby SJ, Firbank MJ, Thomas AJ, et al. 2011. White matter changes in late-life depression: a diffusion tensor imaging study. Journal of affective disorders 135(1): 216-220.

de Guzman AB, Jurado JBN, Juson AJA. 2015. Examining the structural relationship of chronic illness, physical function, life satisfaction, and social support in the development of depression among filipino elderly in institutionalized settings. Educ Gerontol 41(3): 193-206. DOI:10.1080/03601277.2014.918836.

Duberstein PR, Conwell Y, Conner KR, et al. 2004. Poor social integration and suicide: fact or artifact? A case-control study. Psychol Med 34: 1331-1337. DOI:10.1017/s0033291704002600.

Fiest KM, Currie SR, Williams JVA, Wang J. 2011. Chronic conditions and major depression in community-dwelling older adults. J Affect Disord 131: 172-178.

Fiske A, Wetherell JL, Gatz M. 2009. Depression in older adults. Annu Rev Clin Psychol 5: 363-389.

Forsman AK, Schierenbeck I, Wahlbeck K. 2011. Psychosocial interventions for the prevention of depression in older adults: systematic review and meta-analysis. J. Aging Health 23: 387-416. DOI:10.1177/0898264310378041.

Godfrey HPD, Knight RG. 1984. The validity of actometer and speech activity measures in the assessment of depressed-patients. British Journal of Psychiatry 145: 159-163. DOI:10.1192/bjp.145.2.159. 
Gotlib IH. 1992. Interpersonal and cognitive aspects of depression. Curr Dir Psychol Sci 1: 149-154. DOI:10.1111/1467-8721.ep11510319.

Gotlib IH, Lee CM. 1989. The social functioning of depressed-patients - a longitudinal assessment. I Soc Clin Psychol 8: 223-237. DOI:10.1521/jscp.1989.8.3.223.

Haywood KL, Garratt AM, Fitzpatrick R. 2005. Quality of life in older people: a structured review of generic self-assessed health instruments. Qual Life Res 14 1651-1668. DOI:10.1007/s11136-005-1743-0.

Herrmann LL, Goodwin GM, Ebmeier KP. 2007. The cognitive neuropsychology of depression in the elderly. Psychol Med 37: 1693-1702. DOI:10.1017/ s0033291707001134.

Hirschfeld RMA, Montgomery SA, Keller MB, et al. 2000. Social functioning in depression: a review. J Clin Psychiatry 61: 268-275.

Isaac V, Stewart R, Artero S, Ancelin M-L, Ritchie K. 2009. Social activity and improvement in depressive symptoms in older people: a prospective community cohort study. Am J Geriatr Psychiatry 17: 688-696. DOI:10.1097/ JGP.0b013e3181a88441.

Jang Y, Haley WE, Small BJ, Mortimer JA. 2002. The role of mastery and social resources in the associations between disability and depression in later life. Gerontologist 42: 807-813.

Jeste ND, Hays JC, Steffens DC. 2006. Clinical correlates of anxious depression among elderly patients with depression. J Affect Disord 90: 37-41. DOI:10.1016/j. jad.2005.10.007

Karam ZN, Provost EM, Singh S, Montgomery J, Archer C, Harrington G, McInnis MG. 2014. Ecologically valid long-term mood monitoring of individuals with bipolar disorder using speech. In ICASSP, IEEE International Conference on Acoustics, Speech and Signal Processing - Proceedings. pp. 4858-4862. [6854525] Institute of Electrical and Electronics Engineers Inc.. DOI:10.1109/ ICASSP.2014.6854525.

Kessler RC, Berglund P, Demler O, et al. 2003. The epidemiology of major depressive disorder - results from the National Comorbidity Survey Replication (NCS-R) JAMA-Journal of the American Medical Association 289: 3095-3105. DOI:10.1001/ jama.289.23.3095

Lee C-T, Yeh C-J, Lee M-C, et al. 2012. Social support and mobility limitation as modifiable predictors of improvement in depressive symptoms in the elderly: results of a national longitudinal study. Arch Gerontol Geriatr 55: 530-538. DOI:10.1016/j.archger.2012.03.002.

Lee L, Harkness KL, Sabbagh MA, Jacobson JA. 2005. Mental state decoding abilities in clinical depression. I. Affect. Disord 86: 247-258. DOI:10.1016/j.jad.2005.02.007.

Litwin H. 2012. Physical activity, social network type, and depressive symptoms in late life: an analysis of data from the National Social Life, Health and Aging Project. Aging Ment Health 16: 608-616. DOI:10.1080/13607863.2011.644264.

Maxhuni, A., Matic, A., Osmani, V., Ibarra, O.M. 2011. Correlation Between Self-Reported Mood States and Objectively Measured Social Interactions at Work: A Pilot Study. 5th International Conference on Pervasive Computing Technologies fo Healthcare (PervasiveHealth, 2011).

Marks R. 2013. Depressive symptoms among community-dwelling older adults with mild to moderate knee osteoarthritis: Extent, interrelationships, and predictors. American Journal of Medicine Studies 1(3): 11-18.

Mechakra-Tahiri S, Zuzunegui MV, Preville M, Dube M. 2009. Social relationships and depression among people 65 years and over living in rural and urban areas of Quebec. Int J Geriatr Psychiatry 24: 1226-1236. DOI:10.1002/gps.2250.

Muaremi A, Gravenhorst F, Gruenerbl A, Arnrich B, Troester G. 2014. Assessing Bipolar Episodes Using Speech Cues Derived from Phone Calls. Pervasive Computing Paradigms for Mental Health 100: 103-114. DOI:10.1007/978-3-319-11564-1_11.

O'Brien JT, Lloyd A, McKeith IG, Gholkar A, Ferrier IN. 2004. A longitudinal study of hippocampal volume, cortisol levels, and cognition in older depressed subjects. Am J Psychiatry 161(11): 2081-2090.

Office of National Statistics (2012) Population Ageing in the United Kingdom,its Constituent Countries and the European Union. [Online] Available from: http:// www.ons.gov.uk/ons/dcp171776_258607.pdf

Ooi KEB, Lech M, Allen NB. 2013. Multichannel weighted speech classification system for prediction of major depression in adolescents. IEEE Trans. Biomed. Eng. 60: 497-506. DOI:10.1109/tbme.2012.2228646.

Prince MJ, Harwood RH, Blizard RA, Thomas A, Mann AH. 1997. Social support deficits, loneliness and life events as risk factors for depression in old age. The Gospel Oak Object .6. Psychol Med 27: 323-332. DOI:10.1017/s0033291796004485.

Prince SA, Adamo KB, Hamel ME, et al. 2008. A comparison of direct versus self-report measures for assessing physical activity in adults: a systematic review. Int $J$ Behav Nutr Phys Act 5: . DOI:10.1186/1479-5868-5-56.

Prociow PA. 2011. Mobile psychiatry: Personalised ambient monitoring for the mentally ill. (Unpublished doctoral dissertation). University of Nottingham, UK.

Prociow PA, Crowe JA. 2010. Towards personalised ambient monitoring of mental health via mobile technologies. Technol Health Care 18: 275-284. DOI:10.3233/ thc-2010-0590.

Rabbi M, Shahid Ali, Choudhury T, Berke E. 2011. Passive and In-Situ assessment of mental and physical well-being using mobile sensors. In Proceedings of the 13th international conference on Ubiquitous computing (UbiComp '11). ACM, New York, NY, USA, 385-394. DOI: http://dx.doi.org/10.1145/2030112.2030164

Riddle M, McQuoid DR, Potter GG, Steffens DC, Taylor WD. 2015. Disability but not social support predicts cognitive deterioration in late-life depression. International Psychogeriatrics 27: 707-14. DOI:10.1017/S1041610214002543.

Robitaille A, Muniz G, Lindwall M, et al. 2014. Physical activity and cognitive functioning in the oldest old: within- and between-person cognitive activity and psychosocial mediators. Eur J Ageing 11: 333-347. DOI:10.1007/s10433-014-0314-z.

Romero N, Sanchez A, Vazquez C. 2014. Memory biases in remitted depression: the role of negative cognitions at explicit and automatic processing levels. J Behav Ther Exp Psy 45: 128-135. DOI:10.1016/j.jbtep.2013.09.008.

Sabia S, van Hees VT, Shipley MJ, et al. 2014. Association between questionnaire- and accelerometer-assessed physical activity: the role of sociodemographic factors. Am J Epidemiol 179: 781-790. DOI:10.1093/aje/kwt330.

Schwarzbach M, Luppa M, Sikorski C, Fuchs A, Maier W, van den Bussche H, Pentzek M, Riedel-Heller SG. 2013. The relationship between social integration and depression in non-demented primary care patients aged 75 years and older. J Affect Disord 145: 172-178.

Schwarzbach M, Luppa M, Forstmeier S, Koenig H-H, Riedel-Heller SG. 2014. Social relations and depression in late life - a systematic review. Int J Geriatr Psychiatry 29: 1-21. DOI:10.1002/gps.3971.

Sheline YI, Barch DM, Garcia K, et al. 2006. Cognitive function in late life depression: relationships to depression severity, cerebrovascular risk factors and processing speed. Biol. Psychiatry 60: 58-65. DOI:10.1016/j.biopsych.2005.09.019.

Sjoberg L, Ostling S, Falk H, et al. 2013. Secular changes in the relation between social factors and depression: a study of two birth cohorts of Swedish septuagenarians followed for 5 years. J. Affect. Disord 150: 245-252. DOI:10.1016/j.jad.2013.04.002.

Steger MF, Kashdan TB. 2009. Depression and everyday social activity, belonging, and well-being. J. Couns. Psychol. 56: 289-300. DOI:10.1037/a0015416.

Stone AA, Schwartz JE, Neale JM, et al. 1998. A comparison of coping assessed by ecological momentary assessment and retrospective recall. J Pers Soc Psychol 74: 1670-1680. DOI:10.1037/0022-3514.74.6.1670.

Stuck AE, Walthert JM, Nikolaus T, et al. 1999. Risk factors for functional status decline in community-living elderly people: a systematic literature review. Soc Sci Med 48: 445-469. DOI:10.1016/s0277-9536(98)00370-0.

Sturim D, Torres-Carrasquillo P, Quatieri TF, Malyska N, McCree A, Int Speech Commun. 2011. Automatic Detection of Depression in Speech using Gaussian Mixture Modeling with Factor Analysis. 12th Annual Conference of the International Speech Communication Association 2011 (Interspeech 2011), Vols 1-5, 2992-2995.

Sugisawa H, Shibata H, Hougham GW, Sugihara Y, Liang J. 2002. The impact of social ties on depressive symptoms in US and Japanese elderly. J. Soc. Issues 58: 785-804. DOI:10.1111/1540-4560.00290.

Szanto K, Dombrovski AY, Sahakian BJ, et al. 2012. Social emotion recognition, social functioning, and attempted suicide in late-life depression. Am J Geriatr Psychiatry 20: 257-265. DOI:10.1097/JGP.0b013e31820eea0c.

Tanner EK, Martinez IL, Harris M. 2014. Examining functional and social determinants of depression in community-dwelling older adults: implications for practice. Geriatric Nursing 35: 236-240. DOI:10.1016/j.gerinurse.2014.04.006.

Teicher MH. 1995. Actigraphy and motion analysis - new tools for psychiatry. Harvard Rev Psychiat 3: 18-35. DOI:10.3109/10673229509017161.

Teo AR, Choi H, Valenstein M. 2013. Social Relationships and Depression: Ten-Year Follow-Up from a Nationally Representative Study. PLoS One: Public Library of Science 8(4): e62396.

Thomas AJ, Gallagher P, Robinson LJ, et al. 2009. A comparison of neurocognitive impairment in younger and older adults with major depression. Psychol Med 39: 725-733. DOI: $10.1017 /$ s0033291708004042.

Travis LA, Lyness JM, Shields CG, King DA, Cox C. 2004. Social support, depression, and functional disability in older adult primary-care patients. Am J Geriatr Psychiatry 12: 265-271. DOI:10.1176/appi.ajgp.12.3.265.

United Nations, Department of Economic and Social Affairs, Population Division (2013).World Population Ageing 2013. ST/ESA/SER.A/348

Watkins PC, Vache K, Verney SP, Muller S, Mathews A. 1996. Unconscious moodcongruent memory bias in depression. J. Abnorm. Psychol. 105: 34-41. DOI:10.1037//0021-843x.105.1.34.

Wenze SJ, Miller IW. 2010. Use of ecological momentary assessment in mood disorders research. Clin Psychol Rev 30: 794-804. DOI:10.1016/j.cpr.2010.06.007.

Wiktorsson S, Runeson B, Skoog I, Ostling S, Waern M. 2010. Attempted suicide in the elderly: characteristics of suicide attempters 70 years and older and a general population comparison group. Am J Geriatr Psychiatry 18: 57-67. DOI:10.1097/ JGP.0b013e3181bd1c13.

Wolitzky-Taylor KB, Castriotta N, Lenze EJ, Stanley MA, Craske MG. 2010. Anxiety disorders in older adults: a comprehensive review. Depression and anxiety 27(2): $190-211$.

Wolkenstein L, Schoenenberg M, Schirm E, Hautzinger M. 2011. I can see what you feel, but I can't deal with it: impaired theory of mind in depression. J Affect Disord 132: 104-111. DOI:10.1016/j.jad.2011.02.010. 